Running Head: SYSTEM JUSTIFICATION AND HUMOR

\title{
At Whose Expense?
}

\section{System Justification and the Appreciation of Stereotypical Humor Targeting High vs. Low Status Groups}

\author{
Dean Baltiansky* \\ Department of Psychology \\ Stanford University \\ Maureen A. Craig and John T. Jost \\ Department of Psychology \\ New York University
}

Accepted for publication at HUMOR: International Journal of Humor Research

* Corresponding author: dbalti@ stanford.edu

Authors' Note: This article is based on a masters' thesis submitted by the first author to the Department of Psychology at New York University under the supervision of the other two authors. This study was funded by an M.A. Research Award. We thank members of the Social Justice Lab and the Diversity and Social Processes Lab for helpful assistance, support, and feedback. We especially wish to thank Andrea Courtney, Jussi Valtonen, and Jamil Zaki for constructive comments on a previous version of the article.

Analysis scripts, data, stimuli, and supplemental material can be found here: $\underline{\text { osf.io/xr95h/ }}$ 


\begin{abstract}
Many popular comedians tell complicated jokes that involve multiple levels of interpretation. The same joke may be perceived as criticizing or reinforcing the societal status quo, depending on perceivers' assumptions about the target of the punchline (e.g., whether the joke is at the expense of high- or low-status groups). We focused on how such jokes are experienced by listeners who are psychologically prone to justifying (versus challenging) the status quo. In a sample of Mechanical Turk workers $(N=179)$, we explored whether individual differences in system justification would be associated with the appreciation of group-based (stereotypical) humor, depending on the perceived target of the joke. As hypothesized, high system-justifiers found jokes targeting low-status groups (e.g., women, poor people, racial/ethnic minorities) to be funnier than low system-justifiers did. In some cases, low system-justifiers found jokes targeting high-status groups (rich people, European Americans) to be funnier than high system-justifiers did. These results expand upon previous demonstrations that humor appreciation is linked to relatively stable ideological dispositions and suggest that different individuals may perceive complex group-based humor in divergent ways.
\end{abstract}

Keywords: system justification; stereotypical humor; motivated humor appreciation; joke targets 


\section{Whatever is funny is subversive.}

\section{(George Orwell)}

\section{Introduction}

Tuning into the latest Netflix comedy special, one looks forward to hearing Dave Chappelle's latest take on intergroup relations in the U.S. Since his groundbreaking TV program, Chappelle's Show, debuted on Comedy Central more than 15 years ago, his unapologetic comedic style has remained extremely popular in mainstream culture (Rotten Tomatoes 2019). In the 2019 comedy special, Sticks and Stones, Chappelle defended the use of guns against drug addicts, made jokes about Asians and African Americans that many considered to be racially insensitive, broadened a feud with the LGBTQ community, and declared that the "Me Too" movement had gone too far. Unsurprisingly, these comments drew many rebukes (Krauker 2019; NBC News).

However, it is conceivable that the power and popularity of Chapelle's comedy stems from the fact that it oscillates quickly and, in many cases, effectively between criticizing the societal status quo and defending it. This creates an opportunity for his audiences to, in essence, hear what they want to hear: a searing indictment of racism, sexism, classism, and homophobia, or a nod to its occasional reasonableness. If this is true, then Chappelle's brand of humor-and, indeed, that of many other contemporary comedians - may be experienced quite differently by listeners who are psychologically prone to justifying versus challenging the societal status quo. In the present research program, we considered the possibility that individual differences in system justification motivation - the tendency to defend vs. challenge the societal status quowould predict differential reactions to jokes targeting high- as well as low-status groups.

\subsection{Individual differences in system justification tendencies}


In social psychology, the concept of system justification is used to describe the fairly pervasive tendency for people to defend, bolster, and justify aspects of the societal status quo - a tendency that manifests itself both attitudinally and behaviorally (Jost 2020). When it comes to intergroup relations, people often rely on social stereotypes to justify existing societal hierarchies. As Gordon Allport (1954) put it, "the rationalizing and justifying function of a stereotype exceeds its function as a reflector of group attributes" (p. 196). Many stereotypes exonerate the status quo by blaming disadvantaged groups for their plight, ascribing negative characteristics to them that make their suffering seem less unjust (Jost and Banaji 1994). Furthermore, members of disadvantaged groups sometimes internalize a sense of their own inferiority and subscribe to system-justifying ideas that preserve the legitimacy of the overarching social system at their own expense (e.g., Jost and Banaji 1994; Napier et al. 2006; Pacilli et al. 2011). Individuals differ considerably in the extent to which they are motivated to defend vs. criticize the societal status quo, with people who identify themselves as politically conservative much more likely to score high on measures of general, economic, and genderspecific system justification, in comparison with people who identify themselves as liberal or progressive (Jost 2020).

To the extent that system justification is a relatively common motivational tendency, it should influence the creation and reception of nearly all aspects of cultural life, including religion, politics, and entertainment (e.g., Jost et al. 2014). The possibility we focus on in the present article is that individual differences in system justification motivation shape reactions to humor-especially group-based (or stereotypical) humor. To our knowledge, no previous research has explored the possibility that system justification tendencies affect humor appreciation, but there are good reasons to expect that it would. 
Prominent psychological theories of humor suggest that people are especially likely to find a joke funny when they experience it as (a) violating a well-known social norm, as in the case of either a stereotypical joke violating egalitarian expectations or a joke that unexpectedly turns the tables on those who are privileged and powerful, and yet (b) the norm violation is not so extreme as to be regarded as harmful to anyone (Veatch 1998). According to benign violation theory, people are most likely to laugh when they encounter a message that is incongruous with a familiar social norm and, at the same time, not truly malicious (McGraw and Warren 2010). The type of incongruity also matters: social norm violation predicts humor appreciation better than surprise, juxtaposition, and atypicality (Warren and McGraw 2015). In one experimental demonstration, confederates either offered candy to participants or threw it at them, thereby violating a norm, after warning them beforehand or not. Participants who had candy thrown at them without warning found the interaction to be funnier (measured in terms of self-report and behavioral indicators), in comparison with participants assigned to other conditions (McGraw and Warren 2015, Study 6). Findings such as these are taken to indicate that people tend to experience relatively benign violations of normative expectations as humorous.

Importantly, however, individuals are likely to differ considerably when it comes to their normative expectations about stereotypical humor - and especially their assessments of whether it is truly benign. In particular, stereotypical humor disparaging low-status groups should be appreciated more by those who wish to maintain the societal status quo than by those who seek to challenge it. This is because individuals who are chronically high in system justification tendencies hold relatively favorable attitudes about high-status groups and unfavorable attitudes about low-status groups, in comparison with individuals who are chronically low in system justification tendencies (Jost 2020). Consequently, high (vs. low) system-justifiers should be 
more likely to experience jokes targeting low-status groups - and the violation of normative expectations about "political correctness" (the enforcement of egalitarian norms) — as benign. Therefore, our first hypothesis was that people who score higher (vs. lower) on an individual difference measure of system justification, who tend to be politically conservative, would find jokes made at the expense of low-status groups to be funnier (H1).

Conversely, individuals who are chronically low in system justification tendenciesthose who are open to criticizing the legitimacy of the existing social order-should be more likely to enjoy violations of norms that support the status quo and to experience them as benign. Therefore, they should be more appreciative of jokes that call into question the appropriateness of existing social hierarchies. This would include jokes disparaging members of advantaged or high-status groups, which are likely to be experienced as levelling the (perceived) playing field and creating an "illusion of equality" (Kay and Jost 2003; see also Kay et al. 2009). Therefore, our second hypothesis was that people who score lower (vs. higher) on an individual difference measure of system justification, who tend to be politically liberal or progressive, would find jokes made at the expense of high-status groups to be funnier $(\mathrm{H} 2)$.

In a sense, both of our hypotheses are in line with Orwell's classic quip that "Whatever is funny is subversive. Every joke is ultimately a custard pie... a dirty joke is a sort of mental rebellion" (see also Palmer 1988). A question that is left unanswered by Orwell's formulation, however, is what the object of subversion is - and, relatedly, which norm violations are considered to be "benign." An analysis of individual differences in ideology and system justification would lead one to expect that high system-justifiers would enjoy subverting egalitarian norms and proscriptions against mocking those who are socially disadvantaged. Low system-justifiers, on the other hand, would be more likely to enjoy subverting the existing social 
order, which protects those who are advantaged by the status quo from criticism and attack. That is, high system-justifiers would be more likely than low system-justifiers to experience violations of political correctness norms as benign, whereas low system-justifiers would be more likely than high system-justifiers to experience violations of the traditional status quo as benign.

\subsection{Previous research on stereotypical humor}

To our knowledge, no previous research has considered the effects of individual differences in system justification on the appreciation of stereotypical humor. There are, however, a number of studies that are broadly consistent with the notion that individuals differ considerably in the extent to which they enjoy group-based humor and that these individual differences are linked to ideological orientations (e.g., Hodson et al. 2010a; Thomas and Esses 2004). For instance, women who were strongly identified with their gender were found to appreciate jokes making fun of men more than women who were low in gender identification (Abrams et al. 2015). Conversely, women who scored higher on an individual difference measure of hostile sexism against women rated sexist jokes told at the expense of women as funnier than women who scored lower on hostile sexism (Prusaczyk and Hodson 2020).

In other research, men who scored higher on hostile sexism were found to respond in a more sexist manner following exposure to sexist jokes (Ford et al. 2001). In one experiment, for instance, men who were high (but not low) on hostile sexism were more likely to report tolerating a hypothetical case of sexual harassment after reading a vignette in which women and men alike told sexist jokes at the expense of women, in comparison with vignettes in which people told neutral jokes or made sexist but non-humorous statements. Likewise, exposure to sexist humor led men who were high (but not low) in hostile sexism to be less financially supportive of women's organizations in general (Ford et al. 2008). Presumably, these effects 
occur at least in part because conveying sexist material in a humorous way creates the impression that gender prejudice is normatively acceptable and not so serious (see also Ford and Ferguson 2004). That is, writing off group-based disparagement humor as "just jokes" may serve to legitimize hierarchy-enhancing beliefs and assumptions that otherwise might have been considered socially unacceptable (Hodson and MacInnis 2016; Mendiburo-Seguel and Ford 2019).

All of this is consistent with other work suggesting that disparagement humor enhances group cohesiveness, in-group favoritism, and prejudice as well as support for existing social norms and status hierarchies (Ferguson and Ford 2008; Janes and Olson 2000; Maio et al. 1997; Sayre 2001; Terrion and Ashforth 2002). In one experiment, for instance, European American participants who were exposed to comedic skits that contained stereotypical (vs. nonstereotypical) representations of African Americans were more likely to judge a black (but not white) criminal suspect as guilty (Ford 1997). Not surprisingly, members of a low-status group that is targeted by disparagement humor may experience stronger feelings of social exclusion and identity threat (Ford et al. 2019).

Again, it is important to keep in mind that humor can also be subversive of the status quo, as George Orwell proposed. Some jokes call prevalent cultural stereotypes into question or serve to re-appropriate derogatory language — as when African American comedians use the "N word." These rhetorical moves can, in at least some cases, serve to strengthen in-group identification and solidarity among members of disadvantaged groups (Bianchi 2014). Furthermore, joketellers can communicate egalitarian messages by highlighting the perniciousness of social stereotypes and offering, perhaps tacitly, some kind of ideological critique of inequality in society (Hom 2008). 
All of this suggests that people who differ in terms of personality characteristics and ideological orientations are likely to respond quite differently to stereotypical humor. They are also likely to process jokes made at the expense of high-status vs. low-status groups differently. Some message recipients will be eager to laugh at jokes that subvert egalitarian norms associated with "political correctness," whereas others will find humor in jokes that subvert the existing hierarchy. Consistent with this possibility, Hodson and colleagues (2010b) found that Americans and Canadians who scored higher on an individual difference measure of social dominance orientation were more likely to appreciate humor targeted at Mexicans. This result suggests that individual differences in the motivation for group-based dominance may shape perceptions of jokes made at the expense of lower status group targets. However, Hodson and colleagues found no evidence that people who scored lower on social dominance orientation were more appreciative of jokes targeting higher status groups such as Americans or Canadians.

In a nationally representative sample of 1,500 Americans, scores on social dominance orientation and general system justification were modestly correlated at .13 (Jost 2019). Thus, the two psychological variables tend to be positively correlated-especially for members of high-status or advantaged groups (Jost and Thompson 2000) — but they are very clearly distinct. Whereas social dominance orientation captures a motivation to "step on" members of other groups (Sidanius and Pratto 2001), system justification refers to an inherently conservative motivation to defend and justify the status quo - whether doing so happens to be advantageous or disadvantageous to one's own group. Therefore, we investigated the twin hypotheses that high system-justifiers would find jokes made at the expense of low-status groups to be funnier than low system-justifiers (H1), whereas low system-justifiers would find jokes made at the expense of high-status groups to be funnier than high system-justifiers $(\mathrm{H} 2)$. 


\section{Method}

\subsection{Reproducibility}

Anonymized data files, analysis scripts, stimulus materials, measures described in this manuscript, and additional results can be found in this Open Science Framework link: osf.io/xr95h/

\subsection{Participants}

We initially recruited 215 U.S. adults to participate in the study through the Amazon Mechanical Turk (MTurk) platform in exchange for $\$ 2.00$. Because the drawbacks of working with MTurk data are well-known and include participants' lack of careful attention and people from other countries taking surveys through servers that are located in the U.S., we took several precautionary measures with respect to data collection (Kennedy et al. 2018). We utilized TurkPrime's feature to eliminate suspicious Virtual Private Servers to reduce the possibility that participants were taking the survey from outside of the U.S. To minimize the likelihood that automatic responses from bots would be recorded, we granted survey access only to those participants who maintained high approval ratings. During the administration of the survey, participants were asked (at random intervals) to complete three attention checks; responses of those who failed the attention checks were excluded from analysis $(n=36)$. The final sample therefore consisted of 179 U.S. adults $\left(M_{\text {age }}=38.21, S D_{\text {age }}=11.2 ; 56 \%\right.$ female; $79.89 \%$ white; 41.9\% college graduates and $30.7 \%$ have started college but have not completed their degree).

\subsection{Procedure}

At the outset, participants were informed that they would be asked to rate the humor of specific jokes as part of a study focusing on the perception of stereotypical humor. After providing informed consent and completing initial technical and attention checks, participants 
were exposed to 37 randomly ordered audio recordings of mainstream comedians telling stereotypical jokes. For each joke, participants first indicated how funny they found the joke to be. Next, they were asked to determine the social group membership of the joke teller as well as the social group that was the target (or butt) of the joke. Afterward, we administered the general system justification scale and collected demographic information. ${ }^{1}$ Finally, participants were debriefed about the purpose of the study and provided with a code to receive payment.

\subsection{Stimulus materials}

Jokes were selected by the first author after he viewed a large number of mainstream comedians' stand-up performances archived online. Any joke that seemed to target a specific social group — such as drawing on stereotypes of that group or making fun of that group's advantaged or disadvantaged position in society_was considered for inclusion in the study. A special effort was made to identify joke-tellers who were high and low in terms of group status and to identify jokes that targeted high and low status groups. Thus, search terms included the names of well-known comedians who differed in terms of race and gender (e.g., Dave Chappelle, Sarah Silverman, Daniel Tosh, etc.) as well as specific target groups (e.g., white people, black people, men, women), and words related to group-based humor (e.g., "funny stereotypes").

In terms of length, we selected jokes that took less than one minute to tell (with one exception) in an effort to ensure that they were not excessively complicated or elaborate. We

\footnotetext{
${ }^{1}$ We also administered an economic system justification scale and an ideological self-placement item, which were used to validate scores on the general system justification scale. We also asked participants how much they believed that the following groups were "discriminated against today": White Americans, Black Americans, Hispanics/Latinos, Asian Americans, Native Americans, gay men, lesbians, straight men, straight women, obese people, thin people, elderly, teenagers, Christians, Muslims, and Jews. These items were not incorporated in the results reported here, because we decided to conduct analyses collapsing across high- and low-status target groups rather than analyzing jokes about specific target groups separately.
} 
varied the content and perceived group memberships of the comedians and targets as much as possible (given the above constraints) to arrive at a reasonably heterogeneous sample of jokes. To mitigate the effects of celebrity status, we sampled the audio files from the original videos and presented only the sound along with an image of a neutral (non-famous) face of someone who shared the joke teller's group membership (e.g., a white woman); faces were taken from the Chicago Face Database (Ma et al. 2015). During debriefing, participants were asked to providing comments on the study, and five participants indicated that they recognized some of the comedians' voices. When we excluded these participants and re-ran the analyses, we obtained results that were very similar to what is reported here.

\subsection{Measures}

\subsubsection{Humor appreciation}

Participants indicated how funny they believed each joke to be using a 9-point Likert scale $(1=$ Not Funny at All to $9=$ Very Funny), as in previous research by Ford (2000). Participants reported perceived funniness immediately after listening to each joke.

\subsubsection{Perceived target group}

For each joke, we asked participants: "Which social group do you think the comedian is making fun of?" For all jokes, we presented a comprehensive list of 20 possible choices, including "black people," "gays/lesbians," "the elderly," and so on (see supplemental material for the full list). The list therefore included a wide variety of high- and low-status groups in U.S. society. Participants were also given the options not to answer and to select more than one target group to allow for the possibility that some jokes would be perceived as operating at multiple levels of interpretation.

\subsubsection{Perceived group membership of the joke-teller}


We also asked participants: "Which social group do you think the comedian is from?" They were provided with the same list of 20 groups, as noted above, and asked to select "all that apply." This question served as both a check on attention and on the manipulation. Participants were overwhelmingly accurate, providing the correct answer $92.44 \%$ of the time. Thus, the vast majority of our participants paid attention to the stimulus materials and took note of the joketeller's group membership.

\subsubsection{General system justification}

General system justification was measured with the General System Justification Scale (Kay and Jost 2003), an 8-item self-report measure used to assess an individual's perception of the fairness, legitimacy, and justifiability of the American social system. For each item, participants were asked to indicate the degree to which they agreed or disagreed with statements regarding American society on a 7-point Likert scale $(1=$ Strongly Disagree to $7=$ Strongly Agree $)$, such as "In general, I find society to be fair," and "American society needs to be radically restructured (reverse-scored)." We averaged across the 8 items to create a general system justification index in which higher scores indicated a stronger tendency to justify the social system $(\alpha=.89)$.

Consistent with previous research, general system justification scores were correlated with selfidentified political conservatism, $r(177)=.50, p<.001$, and with scores on the economic system justification scale, $r(177)=.58, p<.001$.

\subsubsection{Classification of jokes based on perceived target groups}

For each joke, we therefore distinguished four possibilities for categorical analysis: (1) participants who thought the joke made fun of a high-status group; (2) participants who thought the joke made fun of a low-status group; (3) participants who thought the joke made fun of both high-status and low-status groups; and (4) participants who thought the joke made fun of an 
unrelated group or preferred not to answer. We decided that it was important to include category (3) separately rather than including responses from these participants in analyses based on categories (1) and (2) because we determined that a joke that appeared to simultaneously target high- and low-status group members would be experienced in a qualitatively different manner in comparison with jokes that appeared to target one or the other.

Next, based on the aggregation of individual participants' responses, we classified each joke as belonging to one of three categories: (1) jokes that were widely perceived as making fun of low-status groups; (2) jokes that were widely perceived as making fun of high-status groups; and (3) jokes that were widely perceived as making fun of both high- and low-status groups. In an attempt to create three categories that faithfully represented the distributions of participant responses, we decided to assign jokes to category (3) whenever the absolute value for the difference between the number of participants who thought the joke made fun of a high-status group and those who thought it made fun of a low-status group was less than 40 . This cut-off point was not specified in advance; it was determined only after observing the frequencies of responses. As a check on the reasonableness of this categorization scheme, we read all of the jokes again and confirmed that the jokes categorized in (1) and (2) were indeed unambiguous in terms of the butt of the joke. By and large, these jokes were relatively clear, simple, and had little potential to be understood in a way that differed from the literal meaning.

\section{Results}

We hypothesized that high system-justifiers would find jokes at the expense of low-status groups to be funnier than low system-justifiers (H1), whereas low system-justifiers would find jokes at the expense of high-status groups to be funnier than high system-justifiers $(\mathrm{H} 2)$. To investigate these hypotheses, we constructed a linear mixed effects model, entering participant as 
a random-effect variable, perceived target group and system justification (z-scored) as predictor variables, and humor ratings as outcome variables. Conducting linear mixed effects modelsrather than fixed term multivariate regression models - allowed us to take into account variability in the contents and ratings of specific jokes. Because a considerable proportion of jokes mentioned race or gender, we adjusted for participant race and sex in all models. Analyses were conducted using the 'lme4' package in R. To interpret interaction patterns, we also conducted follow-up simple slopes analyses within each of the joke categories (as a function of group target), also adjusting for participant race and sex.

The analysis yielded two main effects and an interaction. First, there was a significant main effect of participant sex, $b=0.88, S E=0.22, p<.001$. In general, men $(M=4.69, S D=$ 2.33) rated the jokes as funnier than women $(M=3.74, S D=2.50)$. Second, there was a significant main effect of target group status, $b=-1.83, S E=0.52, p<.001$. Overall, jokes that were classified as targeting low-status groups $(M=3.92, S D=2.46)$ were judged to be less funny than jokes that were perceived as targeting high-status groups $(M=4.66, S D=2.47)$. Importantly, however, this main effect was qualified by an interaction with general system justification scores, $\beta=.50, b=.39, S E(b)=.06, p<.001$. As illustrated in Figure 1, individuals who scored higher on system justification found jokes made at the expense of low-status groups to be significantly funnier than did individuals who scored lower in system justification, $\beta=$ $.32, b=.24, S E(b)=.09, p=.006$. There was no statistically significant association between system justification and humor ratings for jokes that were classified as targeting high-status groups $_{s} \beta=-.17, b=-.13, S E(b)=.10, p=.191$, nor for jokes that were classified as targeting both high- and low-status groups, $\beta=.10, b=.08, S E(b)=.09, p=.372$. Thus, our first hypothesis was supported, but our second was not. 


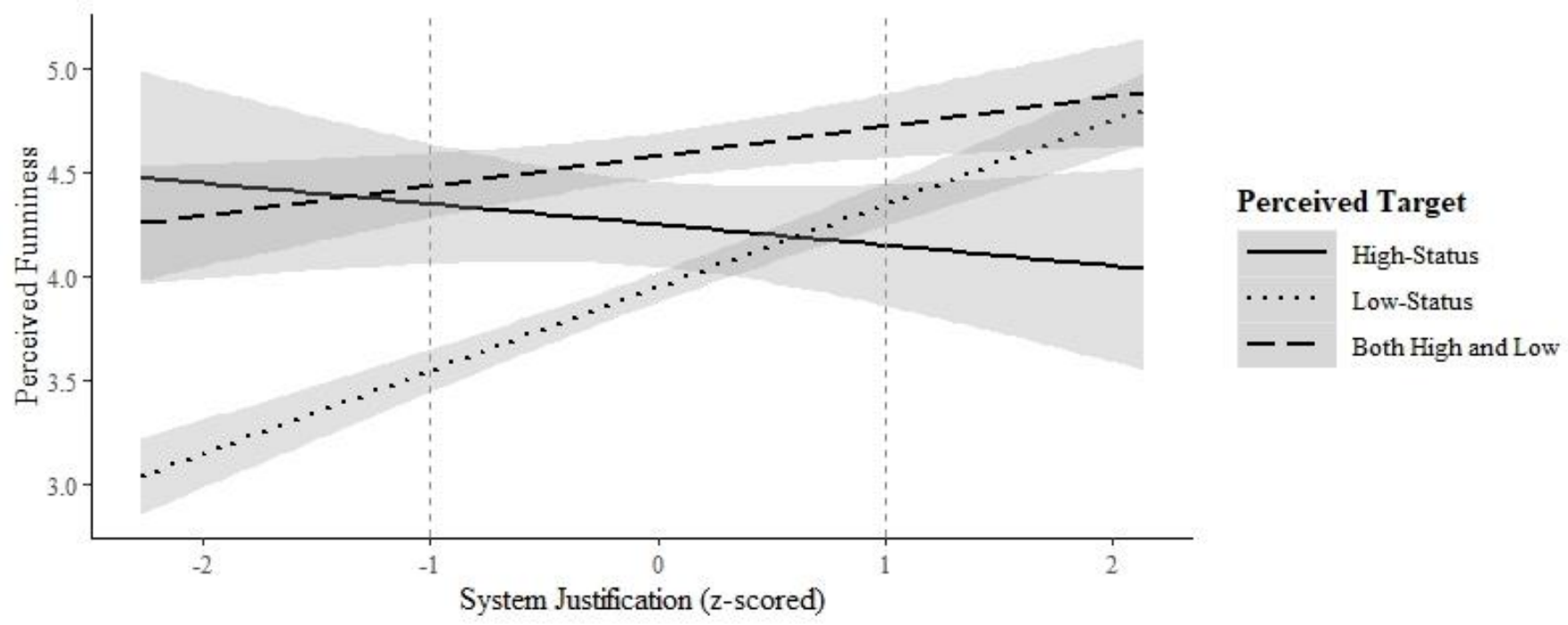

Figure 1: Humor ratings as a function of system justification (z-scored) and target group status.

\section{General Discussion}

The results of this study suggest that the tendency to appreciate stereotypical jokes perceived as targeting high- vs. low-status groups is associated with individual differences in system justification. Specifically, we obtained consistent evidence that high system-justifiers found jokes disparaging low-status groups such as women, poor people, African Americans, Muslims, and Mexicans to be funnier than did low system-justifiers. To a much lesser extent, we also observed — in at least a few cases - that low system-justifiers were more likely than high system-justifiers to appreciate jokes targeting high-status groups such as European Americans and rich people.

Interpreting these results through the lens of benign violation theory, we propose that high and low system-justifiers are likely to differ in terms of which violations of normative expectations are considered to be "benign." Although we did not measure perceptions of benevolence, our findings are consistent with the notion that high system-justifiers found jokes disparaging low-status groups to be less harmful than did low system-justifiers. Future research 
would do well to measure directly the perceived the harmfulness of jokes disparaging high- vs. low-status group members.

These findings comport with other demonstrations that specific types of humor appreciation may be linked to relatively stable ideological dispositions. Much as previous studies highlighted the role of individual differences in hostile sexism (Ford et al. 2008; Ford et al. 2001; Prusaczyk and Hodson 2020), right-wing authoritarianism (Hodson et al. 2010a), and social dominance orientation (Hodson et al. 2010b) when it comes to the appreciation of sexist and racist humor, the present investigation suggests that system justification plays a role in shaping reactions to jokes targeting a variety of high- and low-status groups. Thus, the results we have obtained are consistent with the notion that group-based humor can serve to legitimize the social standing of some social groups while delegitimizing others, as proposed by Hodson and MacInnis (2016).

There are several advantages and disadvantages associated with the methodology we adopted that should be taken into account when evaluating findings and interpretations. Although most studies in this research area have focused on responses to just one or two humorous statements - often one-liners - targeting a single racial or gender group, we presented research participants with 37 different jokes targeting a wide variety of high- and low-status groups. Many of the jokes, which were told by a number of mainstream comedians, were relatively complex and operated at multiple levels of interpretation. This means that our study was reasonably strong in terms of external validity, because we exposed people to precisely the type of stereotypical humor they are likely to encounter in American popular culture. Another advantage of our research program is that we presented people with jokes disparaging high-status as well as low-status groups. To our knowledge, this is the first study to focus on the role of 
ideology in responding to jokes targeting those who are advantaged versus disadvantaged in society.

At the same time, this methodical decision introduced certain ambiguities of joke interpretation. In nearly one-third of the cases, participants disagreed about which group was in fact the butt of the joke. We found that how one interpreted the joke was associated with humor appreciation as a function of one's level of system justification: high system-justifiers were more likely to find jokes funny when they perceived the joke as targeting low-status groups, whereas low system-justifiers were more likely to find jokes funny when they perceived them as targeting high-status groups. Another limitation of our study is that participants were not asked explicitly about which groups they considered to be high and low in social status. It is possible that some respondents perceived a given target group as higher (or lower) in status than other respondents, but it is doubtful — given the degree of consensus that surrounds most cultural stereotypes (Jost and Banaji 1994) — that our classifications of high and low status groups in American society would have been rejected by many participants (see supplemental material for group classifications).

Furthermore, we acknowledge that our sample was limited in terms of demographic and ideological diversity. In general, MTurk samples are more statistically representative of the national population than other types of convenience samples—-such as college studentsfrequently used in psychological research. Still, nearly $80 \%$ of our respondents were European Americans. No doubt this constrains the generalizability of the findings, especially given that people respond differently to jokes targeting their own versus other social groups (Hodson et al. 2010b). Future studies aimed at understanding the role of system justification processes in humor appreciation would do well to make use of larger and more diverse samples to consider higher 
order interaction effects involving the group membership of the receiver and that of the joketeller as well.

\section{Concluding Remarks}

Despite a number of weaknesses, the present study opens the door to a wide range of potential contributions moving forward. It would be especially useful to explore the multiple, possibly conflicting ways in which stereotypic humor encourages people to turn a blind eye toward social injustice and inequality in society while, at the same time, relying upon an implicit recognition of injustice or inequality. For instance, Dave Chappelle's joke about the dramatic contrast in socio-economic environments and quality of life that one encounters when crossing the Bay Bridge from San Francisco to Oakland depends upon the audience members' acknowledgement of harsh realities, even as he appears to make light of them:

But you know what I like about San-Fran and the reason I picked this city to do my special? It was because... of all the major cities in America, somehow people get along here better than anywhere else I've seen in the country. That's right. That's right. And I always admired San-Fran for that and today I realize how you did it. Put all the niggers on the other side of that bridge. There's nothing... shit ain't happy on that side. You leave San Francisco, you're like: bye, thanks for coming to San Francisco. Come back in April, we're having a sale on Birkenstocks. As soon as you get to the other side: Welcome to Oakland, bitch! (Joke 6)

If participants laugh at the joke, they are in some way adopting a critical ideological stance toward society, even as they find congenial ways of tolerating, if not altogether excusing, vast inequality. 
Thus, a promising direction for future research would be to first expose people to various types of humorous messages and then measure their subsequent levels of system justification, perhaps indirectly or unobtrusively. It seems likely that some jokes - especially those that reinforce victim-blaming myths in which members of disadvantaged groups are mocked and made to seem responsible for their plight—would increase at least some respondents' sense that inequality in society is fair, legitimate, and desirable. Other jokes - such as those that draw attention to illegitimate features of our social, economic, and political systems - might have the opposite effect, reducing system justification tendencies, at least temporarily. Because of the ostensibly benign nature of many humorous interventions, jokes that criticize mainstream society may, in a sense, fly "under the radar" and may therefore be less likely to trigger systemdefensive backlash. In this sense, the subversive potential of humor is great, for it can, at least in principle, be used to undermine ideological support for the status quo, much as it is used so often by self-conscious enemies of "political correctness" to bolster existing inequalities.

\section{References}

Abrams, Jessica R., Bippus, Amy M. \& McGaughey, Karen J. 2015. Gender disparaging jokes: An investigation of sexist-nonstereotypical jokes on funniness, typicality, and the moderating role of ingroup identification. Humor 28(2). 311-326. doi: 10.1515/humor2015-0019

Allport, Gordon W. 1954. The nature of prejudice. Cambridge, MA: Addison Wesley.

Bianchi, Claudia. 2014. Slurs and appropriation: An echoic account. Journal of Pragmatics 66. 35-44. doi: 10.1016/j.pragma.2014.02.009

Chappelle, Dave. 2019. Sticks and Stones [Netflix Comedy special]. Lathan, Stan (director). 
Atlanta, GA: Netflix, Inc.

Ferguson, Mark A. \& Ford, Thomas E. 2008. Disparagement humor: A theoretical and empirical review of psychoanalytic, superiority, and social identity theories. Humor 21(3). 283-312. doi: 10.1515/HUMOR.2008.014

Ford, Thomas E. 1997. Effects of stereotypical television portrayals of African-Americans on person perception. Social psychology quarterly 60. 266-278. doi: 10.2307/2787086

Ford, Thomas E. 2000. Effects of sexist humor on tolerance of sexist events. Personality and Social Psychology Bulletin 26(9). 1094-1107. doi: 10.1177/01461672002611006

Ford, Thomas. E., Boxer, Christie F., Armstrong, Jacob \& Edel, Jessica R. 2008. More than “just a joke": The prejudice-releasing function of sexist humor. Personality and Social Psychology Bulletin 34(2). 159-170. doi: 10.1177/0146167207310022

Ford, Thomas E., Buie, Hannah S., Mason, Stephanie D., Olah, Andrew R., Breeden, Christopher J. \& Ferguson, Mark A. 2019. Diminished self-concept and social exclusion: Disparagement humor from the target's perspective. Self and Identity. 1-21. doi: $10.1080 / 15298868.2019 .1653960$

Ford, Thomas E. \& Ferguson, Mark A. 2004. Social consequences of disparagement humor: A prejudiced norm theory. Personality and Social Psychology Review 8(1). 79-94. doi: 10.1207/S15327957PSPR0801_4

Ford, Thomas E., Wentzel, Erin R. \& Lorion, Joli. 2001. Effects of exposure to sexist humor on perceptions of normative tolerance of sexism. European Journal of Social Psychology 31(6). 677-691. doi: 10.1002/ejsp.56

Hodson, Gordon \& MacInnis, Cara C. 2016. Derogating humor as a delegitimization strategy in intergroup contexts. Translational Issues in Psychological Science 2(1). 63-74. doi: 


\section{$10.1037 / \mathrm{tps} 0000052$}

Hodson, Gordon, MacInnis, Cara C. \& Rush, Jonathan. 2010a. Prejudice-relevant correlates of humor temperaments and humor styles. Personality and Individual Differences 49(5). 546-549. doi: 10.1016/j.paid.2010.05.016

Hodson, Gordon, Rush, Jonathan \& MacInnis, Cara C. 2010b. A joke is just a joke (except when it isn't): Cavalier humor beliefs facilitate the expression of group dominance motives. Journal of Personality and Social Psychology 99(4). 660-682. doi: $10.1037 / \mathrm{a} 0019627$

Hom, Christopher. 2008. The semantics of racial epithets. The Journal of Philosophy 15(8). 416440. doi: $10.5840 /$ jphil2008105834

Janes, Leslie M. \& Olson, James M. 2000. Jeer pressure: the behavioral effects of observing ridicule of others. Personality and Social Psychology Bulletin 26(4). 474-485. doi:

\section{$10.1177 / 0146167200266006$}

Jost, John T. 2019. A quarter century of system justification theory: Questions, answers, criticisms, and societal applications. British Journal of Social Psychology 58(2). 263-314. doi: 10.1111/bjso.12297

Jost, John T. 2020. A theory of system justification. Cambridge, MA: Harvard University Press.

Jost, John T. \& Banaji, Mahzarin R. 1994. The role of stereotyping in system-justification and the production of false consciousness. British Journal of Social Psychology 33(1). 1-27. doi: 10.1111/j.2044-8309.1994.tb01008.x

Jost, John T., Hawkins, Carlee B., Nosek, Brian A., Hennes, Erin P., Stern, Chadly, Gosling, Samuel D. \& Graham, Jesse. 2014. Belief in a just God (and a just society): A system justification perspective on religious ideology. Journal of Theoretical and Philosophical 
Psychology 34(1). 56-81. doi: 10.1037/a0033220

Jost, John T. \& Thompson, Erik P. 2000. Group-based dominance and opposition to equality as independent predictors of self-esteem, ethnocentrism, and social policy attitudes among African Americans and European Americans. Journal of Experimental Social Psychology 36. 209-232. doi: 10.1006/jesp.1999.1403

Kay, Aaron C., Czapliński, Szymon \& Jost, John T. 2009. Left-right ideological differences in system justification following exposure to complementary versus noncomplementary stereotype exemplars. European Journal of Social Psychology 39(2). 290-298. doi: 10.1002/ejsp.500

Kay, Aaron C. \& Jost, John T. 2003. Complementary justice: Effects of "poor but happy" and "poor but honest" stereotype exemplars on system justification and implicit activation of the justice motive. Journal of Personality and Social Psychology 85(5). 823-837. doi: 10.1037/0022-3514.85.5.823

Kennedy, Ryan, Clifford, Scott, Burleigh, Tyler, Jewell, Ryan \& Waggoner, Philip. 2018. The Shape of and Solutions to the MTurk Quality Crisis. Available at SSRN. doi: $10.2139 /$ ssrn. 3272468

Krauker, Steve. 9/1/2019. Dave Chappelle's Netflix special 'Sticks and Stones' is as perceptive as ever. Here's why it's controversial. Retrieved from https://www.nbcnews.com/think/opinion/dave-chappelle-s-netflix-special-sticks-stonesperceptive-ever-here-ncna1048566

Ma, Debbie S., Correll, Joshua \& Wittenbrink, Bernd. 2015. The Chicago face database: A free stimulus set of faces and norming data. Behavior Research Methods 47(4). 1122-1135. doi: 10.3758/s13428-014-0532-5 
Maio, Gregory R., Olson, James M. \& Bush, Jacqueline E. 1997. Telling Jokes That Disparage Social Groups: Effects on the Joke Teller's Stereotypes. Journal of Applied Social Psychology 27(22). 1986-2000. doi: 10.1111/j.1559-1816.1997.tb01636.x

McGraw, Peter A. \& Warren, Caleb. 2010. Benign violations: Making immoral behavior funny. Psychological science 21(8). 1141-1149. doi: 10.1177/0956797610376073

Mendiburo-Seguel, Andres \& Ford, Thomas E. 2019. The effect of disparagement humor on the acceptability of prejudice. Current Psychology. 1-12. doi: 10.1007/s12144-019-00354-2

Napier, Jaime L., Mandisodza, Anesu N., Andersen, Susan M. \& Jost, John T. 2006. System justification in responding to the poor and displaced in the aftermath of Hurricane Katrina. Analyses of social issues and public policy 6(1). 57-73. doi: 10.1111/j.15302415.2006.00102.x

Pacilli, Maria G., Taurino, Alessandro, Jost, John T. \& van der Toorn, Jojanneke. 2011. System justification, right-wing conservatism, and internalized homophobia: Gay and lesbian attitudes toward same-sex parenting in Italy. Sex Roles 65(7-8). 580-595. doi: 10.1007/s11199-011-9969-5

Palmer, Jerry. 1988. The logic of the absurd: On film and television comedy. London, UK: British Film Institute

Prusaczyk, Elvira \& Hodson, Gordon 2020. "To the moon, Alica": Cavalier humor beliefs and women's reactions to aggressive and belittling sexist jokes. Journal of Experimental Social Psychology 88.1-11. doi: 10.1016/j.jesp.2020.103973

Rotten Tomatoes. 10/13/2019. The 50 best Netflix Comedy Specials. Retrieved from https://editorial.rottentomatoes.com/guide/the-best-netflix-stand-up-comedy-specials/ Sayre, Joan. 2001. The use of aberrant medical humor by psychiatric unit staff. Issues in Mental 
Health Nursing 22(7). 669-689. doi: 10.1080/01612840119739

Sidanius, Jim \& Pratto, Felicia. 2001. Social dominance: An intergroup theory of social hierarchy and oppression. Cambridge, UK: Cambridge University Press.

Terrion, Jenepher L. \& Ashforth, Blake E. 2002. From 'I' to 'we': the role of putdown humor and identity in the development of a temporary group. Human Relations 55(1). 55-88. doi: 10.1177/0018726702055001606

Thomas, Caroline A. \& Esses, Victoria M. 2004. Individual differences in reactions to sexist humor. Group Processes \& Intergroup Relations 7(1). 89-100. doi: $10.1177 / 1368430204039975$

Veatch, Thomas. 1998. A theory of humor. Humor 11(2). 161-215. doi: 10.1515/humr.1998.11.2.161

Warren, Caleb \& McGraw, Peter A. 2015. Differentiating what is humorous from what is not. Journal of Personality and Social Psychology 110(3). 407-430. doi:

10.1037/pspi0000041 